\title{
O elemento espacial na iconografia do Vale do Amanhecer: os signos de uma nova cosmologia na religião
}

\author{
Altierez Sebastião dos Santos*
}

\begin{abstract}
RESUMO
Apresentamos aqui a análise visual de imagens representativas da iconografia cosmológica do Vale do Amanhecer segundo a metodologia de Gillian Rose. Nosso objetivo é obter, por tal método, um olhar em profundidade sobre aspectos que as imagens não revelariam por si mesmas. Acreditamos que a abordagem segundo os parâmetros de Rose pode revelar elementos insuspeitos na forma como o Vale do Amanhecer consolidou, a partir de narrativas visuais, sua doutrina cosmológica. Os resultados, embora tenham sido bastante esclarecedores, apontam no sentido de ter havido um diálogo com a ficção científica para o estabelecimento de um padrão de comunicação que as religiões tradicionais não possuíam; contudo, esses resultados ainda não são conclusivos.
\end{abstract}

Palavras-chave: Cultura Visual, Vale do Amanhecer, Cosmologia, Análise Visual, Dialogia

THE SPATIAL ELEMENT IN THE ICONOGRAPHY OF THE VALE DO AMANHECER: THE SIGN OF A NEW COSMOLOGY IN RELIGION

\begin{abstract}
We present a visual analysis of representative images on cosmological iconography of Vale do Amanhecer (Brasília) according to Gillian Rose methodology. Our goal is to obtain a deep look on the aspects not revealed in the picture by themselves. We believe the approach according to Rose parameters may reveal unsuspected elements in the way the Vale do Amanhecer has consolidated its cosmological doctrines. The results
\end{abstract}

* Licenciado em História (Faculdade de Educação São Luís) e Filosofia (PUC de Campinas), Doutorando em Ciências da Religião pelo Programa de Pós-Graduação em Ciências da Religião da Universidade Metodista de São Paulo. Endereço: altierezss@gmail.com Acesso ao Lattes: http://lattes.cnpq.br/3610209535743228. 
points towards a sense in which a dialogue with science fiction stablishes communication beyond traditional religions; however, these results are not yet conclusive.

Keywords: visual culture; vale do amanhecer; cosmology; analysis visual; dialogy.

\section{Introdução}

Em nossa pesquisa sobre as imagens do Vale do Amanhecer e sua relação com o cinema, a representação das entidades espirituais Tiãozinho e Justininha, nos chamou a atenção pela forma como a história de ambos ilustra o imaginário sociorreligioso dos membros do Vale do Amanhecer. Este imaginário é marcado pela construção de Brasília e pelo hibridismo social, cultural e religioso que lá ocorreu. $\mathrm{Na}$ análise das imagens, utilizaremos o método preconizado por Gillian Rose (2007, p.30).

Tabela 1: Modalidade tecnológica, composicional e social segundo Rose (2007, p.30)

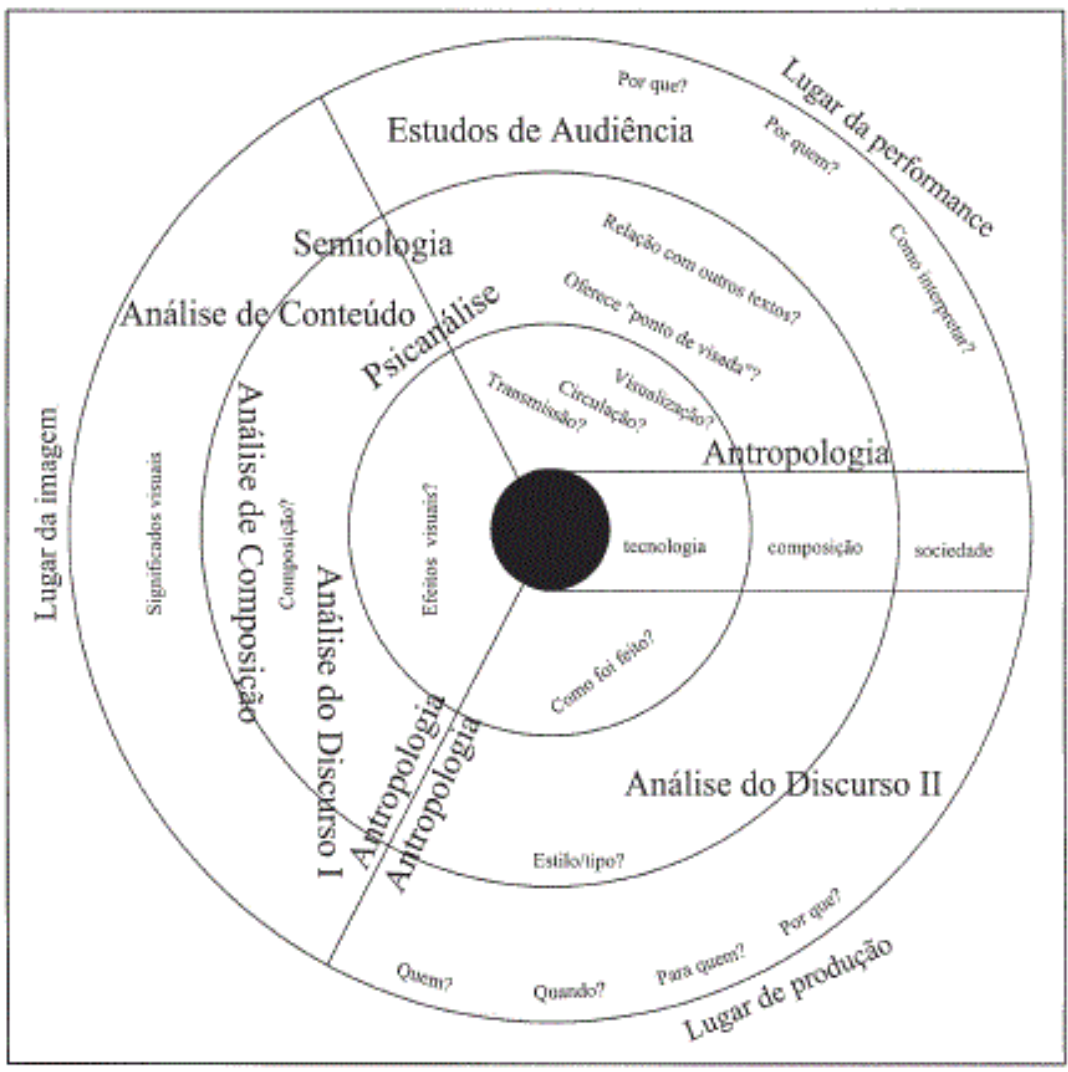


Renders (2015b, p.15) elaborou de forma funcional a percepção de Rose como se segue:

Tabela 2: Modalidade tecnológica, composicional e social segundo Rose (RENDERS, 2015b, p.72).

\begin{tabular}{|l|l|l|l|}
\hline & $\begin{array}{l}\text { Modalidade } \\
\text { tecnológica }\end{array}$ & $\begin{array}{l}\text { Modalidade } \\
\text { composicional }\end{array}$ & $\begin{array}{l}\text { Modalidade } \\
\text { social }\end{array}$ \\
\hline $\begin{array}{l}\text { A criação da } \\
\text { imagem }\end{array}$ & $\begin{array}{l}\text { Feito como? } \\
\text { Com que tipo } \\
\text { de material? }\end{array}$ & $\begin{array}{l}\text { Segue regras de } \\
\text { composição? }\end{array}$ & $\begin{array}{l}\text { Significado } \\
\text { intencionado? } \\
\text { [Significados } \\
\text { Visuais?] }\end{array}$ \\
\hline $\begin{array}{l}\text { A produção } \\
\text { da imagem }\end{array}$ & $\begin{array}{l}\text { Usam-se efeitos } \\
\text { visuais? }\end{array}$ & $\begin{array}{l}\text { Segue-se um gênero } \\
\text { ou um formato? }\end{array}$ & $\begin{array}{l}\text { Por quê? Para } \\
\text { quê? Por quem? } \\
\text { Quando? }\end{array}$ \\
\hline $\begin{array}{l}\text { A recepção } \\
\text { da imagem }\end{array}$ & $\begin{array}{l}\text { É apresentado } \\
\text { como? Está } \\
\text { em exposição? }\end{array}$ & $\begin{array}{l}\text { Relações com outros } \\
\text { textos, imagens, } \\
\text { etc.? }\end{array}$ & $\begin{array}{l}\text { Interpretado } \\
\text { como? Por quem? } \\
\text { Para quem? Por } \\
\text { quê? Quando? }\end{array}$ \\
\hline
\end{tabular}

Sobre a modalidade tecnológica as imagens analisadas por nós foram criadas pelo artista plástico Vilela, que é também médium e membro da doutrina. A criação das imagens segue, além dos padrões e técnicas de pintura convencionais, uma característica própria, que é a atribuição da atividade do artista às esferas espirituais. É do conhecimento dos membros que Vilela realiza seus trabalhos em estado de mediunidade, por isso as obras são a resultante do esforço do médium e das intuições que lhe trazem os espíritos. Os materiais sobre os quais ele desenvolve seu trabalho são variados, utilizando desde técnicas de aquarela a óleo e pintando em telas, paredes e figuras ao ar livre. Vilela pinta sempre por orientação espiritual e ao longo dos anos deu forma a incontáveis entidades do além. Entre os muitos trabalhos que realizou está o da representação dos mentores que cada pessoa ou grupo espiritual possui, razão pela qual ele transferiu para as telas milhares dessas representações; em decorrência da grande procura, ele especializou-se em técnicas de informática e agora pinta também com o auxílio de programas de computação, pois assim pode atender à grande demanda por seu trabalho. 
As figuras criadas por Vilela possuem muitas variáveis, dependendo se ele representa seres humanos quando encarnados na Terra, seres humanos em trabalhos siderais na forma espiritual, seres espirituais do bem ou do mal e seres espirituais de outros planetas, como muitos dos Ministros, Cavaleiros e Príncipes do Planeta Capela, que possuem algumas particularidades fisionômicas.

Suas obras, conforme mencionado antes, são representadas com variadas técnicas e estão expostas em lugares como salas residenciais, hotéis, bibliotecas e ambientes públicos no Distrito Federal, entre outros. No espaço iniciático do Vale do Amanhecer praticamente toda a representação iconográfica é trabalho de Vilela, que está presente no Templo Mãe, na Pirâmide, Estrela Candente, Turigano etc. Em áreas livres da cidade sagrada há obras como as imagens das princesas representadas em torno do Lago Mãe Iara e outras medindo até nove metros de altura. Além dessas formas de exposição, suas imagens ilustram livros doutrinários ou acadêmicos que abordam o fenômeno do Vale do Amanhecer e também se transformaram em adesivos para automóveis, litografias para serem trazidas na carteira, cartões-postais etc.

A respeito da modalidade composicional as regras de composição são bastante claras: além da inspiração que o artista acredita receber do mundo espiritual, ele quase sempre representa as imagens sem perspectiva, com apenas o busto ou o rosto dos personagens e estes olhando o observador de frente, olhos nos olhos. Essas regras de Vilela tornam sua arte facilmente reconhecida, pois há algumas características que estão presentes em quase todas as peças: olhos sombreados, sobrancelhas delineadas e espessas, atributos étnicos (indígenas, africanos, orientais ou "espaciais"), cores quentes e tons degradês. Os personagens são estáticos, sugerindo um estágio de serenidade e inteligência avançado (quando espíritos evoluídos) e tenso e perigoso (quando não evoluídos).

O gênero de suas imagens é preferencialmente o iconográfico, já que representa temas espirituais; dentro desta perspectiva, a ênfase nas representações recai sobre entidades individuais. Há poucas pinturas retratando ações coletivas ou eventos quotidianos. O tema do espaço sideral e da civilização tecnológica mescla-se com temas míticos próprios. Na Casa Grande, local onde viveu Tia Neiva há um gênero pictórico provavelmente derivado das antigas representações cristãs 
dos "Dois caminhos" (abundantes nas tradições católica e reformada até meados do século XX feitas a partir da reflexão do Evangelho de S. Mateus, cap. 7). São mapas de uma geografia espiritual que incluem lugares onde Tia Neiva esteve e descreveu a Vilela, como o Reino das Sombras, o Umbral, as regiões das cavernas, os albergues espirituais, as escolas da espiritualidade até o plano espiritual superior, réplica da cidade celeste cristã. A diferença é que não são dois os caminhos, mas muitos, e todos, mesmo os que passam pelo Umbral, chegam ao Plano Superior (tais trabalhos não podem ser fotografados ou reproduzidos). As imagens que analisaremos aqui têm um referencial direto nos textos doutrinários do Vale. Mas não é apenas com tal referencial que as imagens se relacionam. Elas realizam um amplo diálogo com a construção de Brasília, com a ciência, com o cinema de ficção científica.

Acerca da modalidade social podemos dizer que estas imagens complementam o corpus doutrinário ao ilustrar as revelações de Tia Neiva e auxiliam na construção de uma nova compreensão do lugar da Humanidade na Terra e no Universo. É por essas imagens que passa a recriação de um sentido coletivo à comunidade imaginária do Amanhecer, que é ampla, inclui toda a Humanidade da Terra e as outras "humanidades" dispersas pelos milhões de galáxias deste e de outros Universos.

Esta intencionalidade é direcionada às pessoas que assistiram a uma virada social e cultural na metade do século XX, cuja melhor representação foi a construção de Brasília. Havia a esperança de que o Brasil rural de então levantaria voo em direção ao futuro. Esse otimismo nacionalista pacífico foi alimentado desde o período do Reinado. O País do futuro era uma realidade sempre iminente que foi frustrada. Quando Tia Neiva começa a construir o imaginário do Vale é possível que essa frustração nem fosse tão determinante, embora estivesse presente; a grande tarefa que ela vislumbrou foi a conciliação do novo lugar do ser humano em uma cosmologia mais conforme às descobertas das Ciências e que dialogasse com a tecnologia e novas possibilidades de uma existência mais completa e feliz. Feita esta explanação, passemos agora a analisar o contexto dialógico do surgimento do Vale do Amanhecer e a relação das imagens iconográficas com a estética futurista, e a cosmologia. 


\section{Considerações iniciais sobre o contexto do vale}

De acordo com Senra (2010) a mobilização humana para o território demarcado como Distrito Federal iniciou-se em 1956, quando o Governo enviou 256 trabalhadores para realizarem os primeiros trabalhos demarcatórios. No ano seguinte eles já eram 2.500 e em 1958 a população operária somava 28.000 pessoas, número que aumentava à razão de 2.100 pessoas por dia. Em 1959, quando aconteceu o primeiro censo, a população migrante era de 55.737 pessoas, mas já havia 7.361 nascidos no território da futura capital ${ }^{1}$. Desses migrantes, predominantemente vindos dos Estados de Goiás, Minas Gerais e Bahia, cerca de dois terços eram homens. Nos anos seguintes o contingente populacional continuaria crescendo com os grupos de diversas regiões que traziam em suas bagagens sonhos, esperança e fé.

Os gastos estimados para a construção da cidade foram de entre de 1 bilhão e 1 bilhão e meio de dólares (atualmente um número em torno de 83 bilhões de dólares), conseguidos por empréstimos externos e emissão de papel-moeda, embora o valor total possa ainda variar devido à falta de clareza dos documentos e mesmo à falta de controle sobre os gastos. Quase todos os materiais utilizados foram transportados por avião em um tempo em que o transporte mais utilizado em todo o País ainda era o de tração animal.

Assim, o Vale do Amanhecer é entendido dentro das referências culturais, ideológicas e econômicas que a construção de Brasília movimentou. Naquele momento em que o Brasil firmava sua identidade nacional, ela significou a refundação de um mundo. Toda a intensa mobilização nacional para criar o novo axis mundi brasileiro ficou marcado na consciência coletiva da nação. Ao mesmo tempo havia uma promessa de tempos melhores que a nova cidade traria não só ao seu entorno, mas a todo o Brasil. Uma promessa que não se cumpriu. É no esforço por recontar um mundo perdido e consolar os que foram excluídos existencial e geograficamente que a visão existencial da doutrina do Amanhecer se estrutura.

Embora a construção da Capital seja, de certa forma, o principal fator para a formação do Amanhecer, não é o único, pois ele surgiu den-

1 Atualmente a população de Brasília gira em torno de aproximadamente 2.852.372, segundo a estimativa do IBGE para 2014. 
tro de uma dinâmica de fronteiras, com o entrecruzamento de diferentes expressões sociais, culturais e religiosas. Brasília representou a um só tempo o território do passado e do futuro, do antigo e do novo, dos aviões e das tropas de mulas, dos candangos e dos ministros. Mikhail Bakhtin conceituou o movimento de encontro com o termo dialogia. Para ele, dialogia ou dialogismo é a definição de como o processo de interação entre textos ocorre em uma polifonia; tanto na escrita como na leitura, o texto não é visto isoladamente, mas sim correlacionado com outros textos, discursos ou enunciados. E por estes conceitos Bakhtin entende toda manifestação humana. Assim podemos entender Brasília como a construção de um grande texto onde diferentes vozes se fizeram presentes: ciência, tecnologia, religião, política e a arte etc. Traços dessa origem polifônica e dialógica podem ser percebidos em sua iconografia, que tem muito a revelar sobre as relações entre religião, imagem, ciência, cosmologia entre outros diversos aspectos.

\section{A estética futurista na iconografia do vale}

A cosmovisão do Amanhecer integra em seu corpo doutrinário uma temporalidade que abrange o passado histórico da Humanidade, o "precário" presente do planeta Terra e o futuro espacial que será marcado pela evolução tecnológica, mas principalmente moral ${ }^{2}$.

Deste modo a iconografia contempla igualmente as três dimensões temporais, representando nas pinturas de Vilela e de outros artistas, composições que evocam a história das grandes civilizações passadas como Inca, Maia, Asteca, Egito Antigo, China etc., das quais o Povo Jaguar $^{3}$ é descendente. Outras representações iconográficas são da época

2 O futurismo de Brasília - que em sua origem era também um “futurismo moral”, isto é, a nova capital seria o locus da ética e dos bons políticos - provavelmente foi importante no reforço da concepção de evolução moral. O tempo futuro, na doutrina do Amanhecer, não se dará apenas em termos técnicos, científicos e espaciais, mas ocorrerá, sobretudo, na esfera da moralidade humana.

3 "Povo Jaguar" ou "Povo de Jaguar" são expressões que os membros da doutrina usam para referir-se à coletividade espiritual do Vale do Amanhecer. Segundo a doutrina do Vale esta coletividade foi banida do Planeta Capela por ser composta de espíritos muito primitivos e de baixo padrão moral. O exílio na periferia da galáxia mais humilde, no planeta mais elementar e sob precárias condições foi a condição para que em tempos futuros todos pudessem regressar a Capela. $\mathrm{O}$ expurgo teria ocorrido há mais de $30 \mathrm{mil}$ anos e a vinda de Tia Neiva ao mundo marca o início do regresso dessa coletividade espiritual que trouxe evolução e civilização à Terra enquanto aqui esteve. Sempre segundo a 
presente e mostram a fase atual em que os seres humanos estão prestes a encerrarem um ciclo evolutivo e iniciarem o último de uma série multimilenar. Por fim há a representação do futuro, que é uma mescla de futuro da alma e futuro da civilização material.

Este será, segundo Tia Neiva, o tempo que o gênero humano alcançará sua evolução moral e técnica e terá permissão da Espiritualidade Maior para explorar o Cosmos e entrar em contato com outras civilizações extraplanetárias. Por esse motivo muitas das representações envolvendo espíritos que já se encontram nesse patamar evoluído são oferecidas com adereços tecnológicos, roupas que lembram trajes espaciais, a bordo de espaçonaves, com cidades futuristas ao fundo ou orbitando corpos celestes desconhecidos para nós.

Em nossa pesquisa deparamo-nos com a história de Tiãozinho e Justininha, que para os membros do Amanhecer são espíritos que já realizaram, por meio de sucessivas reencarnações, sua evolução moral, e mesmo pertencendo à temporalidade contemporânea (pois viveram fisicamente no século XX), já fazem parte da nova etapa sideral e espiritual. Por isso escolhemos analisar as pinturas que retratam a trajetória do casal, mencionada por Tia Neiva em vários escritos e narrada no livro Pequenas histórias, da década de 1970.

Resumidamente, Tiãozinho fora um fazendeiro sul-mato-grossense nascido em fins do século XIX, por volta de 1897, batizado com o nome de Sebastião Quirino de Vasconcelos e falecido em 1915. Era de família rica e quando completou 18 anos, recebeu a herança adiantada e saiu acompanhado de seus criados em uma jornada para comprar uma grande boiada, o que fez em uma fazenda situada na fronteira do Brasil com o Paraguai, de propriedade de um senhor paraguaio chamado Germano Perez. Nesta fazenda Tiãozinho encantou-se com a filha do proprietário, Justininha, de cabelos louros e olhos negros. Após um ano casaram-se e foram muito felizes. Em uma fatalidade, porém, a morte os surpreendeu quando navegavam em uma chalana com destino à cidade

doutrina, as grandes civilizações do passado humano foram obra da ação do Povo Jaguar. Por diversas vezes Tia Neiva menciona ter sido Cleópatra, Nefelitite, Natashan e outras personalidades da História Antiga. Ela também costumava desvendar as identidades de vidas passadas dos membros do Vale; enquanto ministrava suas exposições, era comum dizer "Vejo aqui um senador romano", "Você foi o imperador Adriano" e assim por diante. 
de Ponta Porã, quando tinham apenas sete meses de casados. Abaixo algumas das representações do casal feitas por Vilela ${ }^{4}$ :

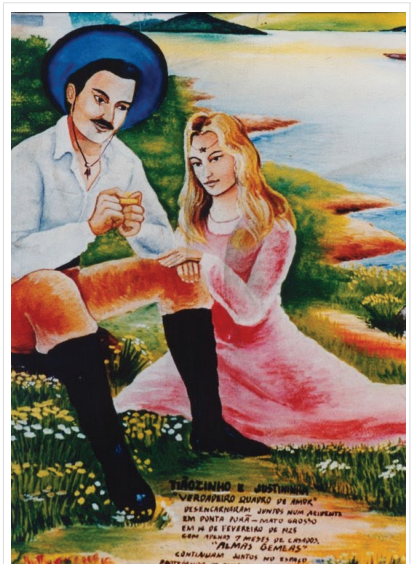

Figura 1: Tiãozinho e Justininha - Pintura de Vilela*. Disponível em: http:// temploacaleno.webnode. com.br/album/mentores/ ti\%C3\%A3ozinho\%20e\%20 justininha-jpg/. Acesso em 22 de Maio de 2015.

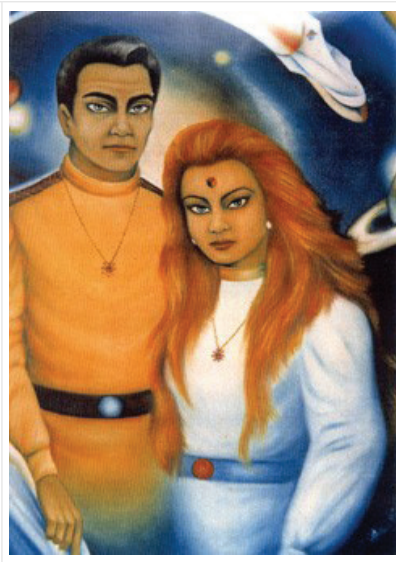

Figura 2: Tiãozinho e Justininha no espaço, Pintura de Vilela, téc. desconhecida, 1989. Disponível em: $h t t p: / /$ valedoamanheceringlaterra. blogspot.com.br/2013/05/paitiaozinho.html

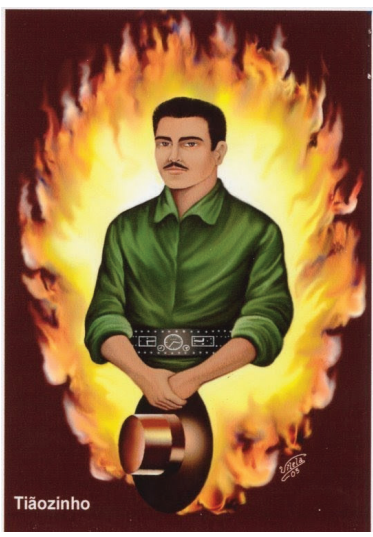

Figura 3: Tiãozinho/Stuart. Pintura de Vilela. Óleo, sem data. Disponível em: http:// temploacaleno.webnode. com.br/images/200000539Of53c0fab2-publicl Ti\%C3\%A3ozinho.jpg

Na figura 1 chama a atenção o fato de a moça ter os cabelos louros e olhos negros, constituição física diferente do tipo físico latino ou indígena. $\mathrm{O}$ adereço que ela usa é uma referência às indumentárias das ninfas do Vale. O protagonista, por outro lado, enrola fumo preparando um cigarro, também uma possível referência a este hábito quase unânime nos membros da doutrina até hoje. $O$ chapéu não é o clássico pantaneiro, de palha, embora suas vestes se assemelhem às das pessoas do meio rural do Brasil de inícios do século XX. Uma natureza plástica, às margens de um rio completa a cena para evocar a geografia certamente comum aos candangos, pois apresenta um cenário que

4 Todas as pinturas reproduzidas aqui são de divulgação da Doutrina do Vale do Amanhecer e foram realizadas pelo artista plástico Vilela, que é médium e membro da doutrina. As imagens não possuem datação.

* A legenda diz: “Tiãozinho e Justininha - 'VERDADEIRO QUADRO DE AMOR'-Desencarnaram juntos num acidente em Ponta Porã - Mato Grosso em 14 de Fevereiro de 1925 [sic] com apenas 7 meses de casados. 'ALMAS GÊMEAS'. Continuam juntos no espaço protegendo os casais". 
genericamente evoca uma paisagem rural e bucólica de um País ainda rural e bucólico, com natureza presente no quotidiano das pessoas. É um cenário saudosista, que diz mais aos migrantes dos Estados do entorno do Distrito Federal que seu clima quente, seco e empoeirado. As roupas do personagem tanto podem ser as de um fazendeiro pecuarista do início do século quanto de condutores de caminhões ou mestres de obras do Plano Piloto (a própria Tia Neiva posou em fotos vestida de maneira semelhante à frente de seus caminhões).

Contudo a história do casal não termina com o acidente que os leva à morte. O caboclo Tiãozinho e sua "alma gêmea" Justininha após de morrerem, passam a viver no espaço, onde participam de missões espirituais a bordo de suas chalanas cósmicas. Na figura 2 os vemos em uniformes espaciais: o casal agora olha para o espectador, e tem uma atitude de tranquilidade e confiança, pois já alcançaram a vida no além. O fundo contém alguns corpos celestes e uma nave (chalana), bastante parecida com os ônibus espaciais do final do século XX. A figura evoca as concepções de família e futuro, pois coloca o casal protagonista em uma perspectiva póstera, visivelmente confiantes e satisfeitos. Não seria esta a esperança que as pessoas tinham ao deixar suas vilas para construir a cidade do futuro?

A figura 3 Vilela retrata o que Tia Neiva, através de outras narrativas, revelou de Tiãozinho em sua vida no espaço sideral. De acordo com os relatos, ele graduou-se em estudos espaciais com a missão de auxiliar no governo espiritual de planetas. Ele agora possui uma identidade que lhe dá cidadania espiritual, sendo lá chamado por outro nome:

(...) a mobilidade de Tiãozinho e a maneira como ele se faz aceitar pelos encarnados, deram-lhe importante papel na presente missão de preparo da Humanidade para o III Milênio. Nos primeiros sete anos de ação entre nós, ele graduou-se como Engenheiro Sideral, especialidade do mundo espiritual que trata de problemas planetários. Ele possui uma chalana, nome que nosso grupo dá a certas astronaves, e é o comandante de uma nave-mãe, que chamamos estufa (...). À guisa de explanação, Johnson disse que, como Capelino, ele se chamava Stuart e era o responsável pela Torre de Desintegração (SASSI, 1990, p. 34).

A figura 3 encontra-se no interior do Templo Mãe. A camisa simples e o chapéu na mão, assim como o olhar calmo do antigo boiadeiro 
quase fazem pensar que ele está usando uma guaiaca, quando na verdade é um cinto com controles e medidores eletrônicos, adereço que indica agora sua dupla pertença: um sertanejo brasileiro que é também cidadão interplanetário. As flamas são uma referência à nave-mãe Estrela Candente, capitânia da frota estelar capelina, da qual ele é comandante. Nesta nave (que cruza o espaço sideral a partir da Constelação do Cocheiro para interferir positivamente nos destinos da Terra e dos espíritos em evolução aqui) encontra-se o centro do poder decisório a partir do qual Pai Seta Branca dirige os destinos espirituais da Terra e trava contínuas batalhas contra os "bandidos do espaço" e "falcões" (espíritos malfeitores) que governam espiritualmente Brasília.

A famosa figura 4 situa Tiãozinho/Stuart na ponte de comando de Estrela Candente. Tia Neiva frequentemente narrava em suas prédicas os encontros que tinha com o personagem ou entidade, como em uma das vezes em que ele levou-a ao Planeta Capela:

No mesmo instante, ela sentiu-se transportada [por Tiãozinho] para o interior de uma nave, muito parecida com aquela em que estivera antes. Na complicada cabine havia outro Capelino, que lhe foi apresentado por Johnson, com o nome de Eris. Enquanto falavam, os dois manipulavam alavancas e botões. Abriu-se, então, uma enorme comporta, e Neiva extasiou-se com o que viu. Ali, bem perto, como se estivesse ao alcance de suas mãos, estava Capela! (SASSI, 1974, pp. 34-35).

Por conta de tal familiaridade, há outras representações visuais que se relacionam aos ensinamentos e peripécias do herói espacial, como a da figura 4, na qual ele é representado junto de seus companheiros de jornada no interior de uma nave. Da esquerda para a direita, Stuart, Johnson Plata, Zaros, Gork e Eris: 


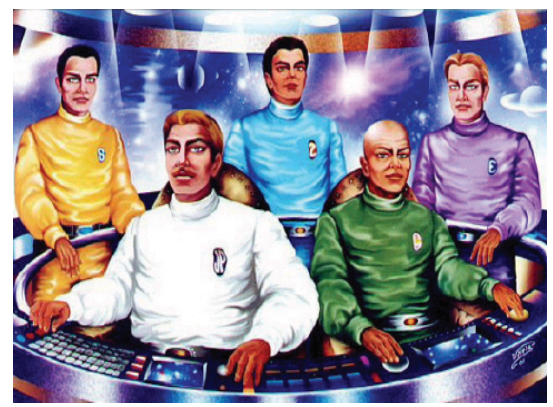

Figura 4: Tripulação da Estrela Candente. Desenho de Vilela, Anos 1970. Disponivel em: http://aspirantevalelasaro.no.comunidades.net/ index.php? pagina $=1680042176$ Acesso em 20 Maio 2015.

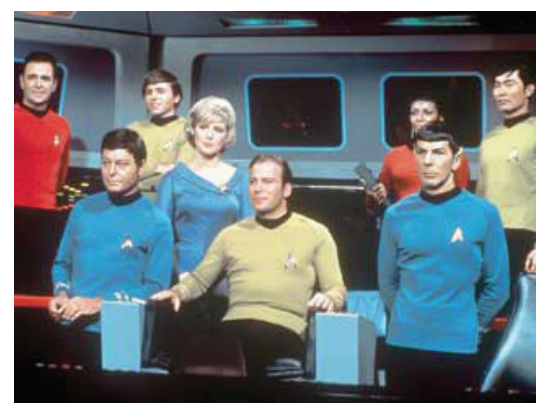

Figura 5: Tripulação da Enterprise, da série Jornada nas Estrelas (1966). A figura é da terceira temporada. Disponivel em: http://lazer.hsw.uol. com.br/star-trek2.htm. Acesso em 20 de Maio de 2015.

Com roupas futuristas, eles são apresentados pelo Vale como integrantes do Comando Capelino, empenhados na luta contra as forças negativas. A figura os situa no ambiente interior de uma nave. A tela ao fundo revela uma perspectiva espacial e todos se portam com altivez, compenetrados no que parece ser a condução do veículo. Não há mulheres e o tipo físico representado é predominantemente o caucasiano, já que quatro dos integrantes têm olhos claros, talvez por influência dos heróis do cinema. Os três personagens centrais têm o tom de pele um pouco mais escuro que os das extremidades, morenos como os candangos.

As figuras 3 e 4 podem ser entendidas na mesma linha e revelam o sucesso que Tiãozinho alcançou em suas atividades, sempre confiante que o porvir seria melhor. É importante lembrar que esta é a mensagem central dos movimentos milenaristas e que certamente fornecia um horizonte de sentido aos migrantes que compuseram o Vale.

\section{O vale do amanhecer e a nova cosmologia}

Aqui queremos considerar um ponto importante: não seria a aproximação da iconografia do Vale com o cinema de ficção científica uma forma (ou necessidade) de expressar religiosamente uma nova cosmologia?

Por muitos séculos o Ocidente entendeu a Terra como centro do Universo, à qual se subordinavam os demais corpos celestes. Embora a esfericidade da Terra e até mesmo a medida de sua circunferência já 
fossem hipóteses aceitas 5 , ainda não se concebia o mundo como "mero" corpo celeste participando da dinâmica astronômica. A própria concepção de Universo seguia as formulações de Aristóteles e de São Tomãs de Aquino, com a Terra sendo envolta por outras esferas celestes (os Sete Céus) às quais as estrelas e planetas estariam grudadas. A centralidade terrestre só seria contestada por Nicolaus Copérnicus no século XVI e por Galileu Galilei no século XVII, que, ao precisarem que o centro do sistema solar seria o próprio Sol, enfrentaram problemas com a Igreja. Por esse modelo, os planetas realizavam órbitas perfeitas em torno da estrela, o que foi derrubado pelas observações de Johannes Kepler ao perceber a complexidade de muitas órbitas. Ainda no século XVII Isaac Newton formulou a lei da gravitação universal que tornou provável as teorias cosmológicas precedentes do movimento dos astros. O século XX seria o das grandes descobertas espaciais, com Albert Einstein propondo a Teoria da Relatividade (que forneceu a estrutura para uma dinâmica espacial do Universo) em 1917; com Alexander Friedmann e a contração e expansão do cosmos em 1922; Edwin Hubble, que identificou o movimento das galáxias em 1929. Em 1927 e 1931 o padre Georges Lemaître postulou o que viria a ser a Teoria do Big Bang. Em 1965 Arno Penzias e Robert Woodrow Wilson detectaram, por meio da radiação isotópica, a antiguidade do Universo. Muitas outras descobertas ocorreram e colocaram a existência humana em uma escala ínfima diante do gigantismo do cosmos. Isso colocou várias questões para o autorreferenciamento humano. Inclusive religiosamente, pois a nova conformação não apenas questionava a antiga formulação cristã, como a restringia diante de dados científicos.

O cristianismo, religião marcada por simbologia, conceitos e referencial agrários situava teologicamente a Humanidade como o ápice da criação e a Terra como o centro da realização divina. A Terra, obra-prima

Erastóstenes, no Egito, havia suposto e calculado a circunferência da Terra em cerca de 40.000 quilômetros, com relativa precisão no século III a. D., medida esta que foi utilizada, com algumas variações, por filósofos, matemáticos e geômetras antigos. No século I a.C. Alexandrino Estrabão cogitou a hipótese da circunavegação e supôs inclusive a existência de terras continentais entre a Ibéria e a Índia. No século II da Era Cristã Claudio Ptolomeu apresentou a teoria que subordinava os demais corpos celestes à centralidade da Terra, entendida como esférica, que, então, seria o centro do sistema. Quanto à "teoria da Terra plana", surgiu no século XVIII, no período Iluminista, como tentativa de desqualificar o pensamento medieval. 
da Divindade era também onde ela descansava os pés, na expressão bíblica e a narrativa do Gênesis marcava o início da história do mundo.

Os novos paradigmas obrigaram a religião a ter diversas reações, que variaram entre a interpretação fundamentalista (literal) dos textos sagrados e sua compreensão metafórica. Mesmo assim criou-se uma distância entre o que a coletividade professava e o que cria.

Mesmo assim a mudança cosmológica de um Universo fixo e imutável para outro dinâmico, acelerado e em mutação constante influenciou e modificou as condições da experiência religiosa. Renders (2015) liga as descobertas cosmológicas às mudanças na experiência religiosa e temporal. Para ele, a religiosidade pré-moderna favorecia uma valorização do passado, estabilidade e continuidade, cujos rituais cíclicos e imutáveis garantiam a permanência da ordem sagrada (cf. p. 431). Com a mudança introduzida por Copernicus na modernidade, a ênfase temporal se deslocou do passado para o futuro. Ao mesmo tempo desenvolveu-se uma compreensão não estática da realidade, com a possibilidade de mudanças, reformas, revoluções. Para Renders, na pós-modernidade as novas descobertas

radicalizaram a sensação de estar no cosmo do ser humano. Ser parte de um cosmo composto por cerca de 100 bilhões de galáxias, em movimento, em aceleração, desafiou ainda mais a ideia da humanidade como coroa da criação e objetivo principal da criação do universo. Se a ênfase temporal da pré-modernidade foi o passado, e da temporalidade moderna o futuro, a pós-modernidade se caracteriza pela ênfase no presente [...]. Isso resulta em uma perda dupla: por um lado, das tradições, por outro lado, das utopias. (2015a, p. 436).

A mudança da concepção do espaço resultou na mudança da temporalidade e a mudança da relação com o passado e o futuro mudou também a relação com o espaço. As distâncias foram encurtadas e o tempo para a realização das tarefas foi reduzido às mínimas possibilidades. Todas as coisas são fugazes: o estar, as sensações, até mesmo a própria existência. A tradição religiosa permaneceu ligada a ritos agrários e ciclos estáticos, pouco dialogando com a nova realidade.

Situado neste contexto de pós-modernidade, o nascimento do Vale do Amanhecer teve como interlocutores todos os questionamentos levantados acima. É preciso que se diga que essa "interlocução" foi em 
muito facilitada pelo ufanismo nacionalista com feições positivistas com que a coletividade brasileira tentava se firmar em termos de identidade. O positivismo enquanto doutrina e prática esteve fortemente presente na cultura média brasileira. A procedência de Tia Neiva de ambientes kardecistas (comungantes de vários aspectos comtianos) favoreceu a absorção da primazia científica, do evolucionismo moral e da organização em todas as esferas materiais e espirituais.

A divergência entre a mentalidade pós-moderna e a cosmovisão pré-moderna abriu espaço para novas possibilidades de pensar a transcendência a nível prático. Por tal espaço aberto, novos discursos sobre o além e o aquém se apresentaram utilizando categorias que, sendo ausentes no tempo antigo, eram compreendidas no novo tempo. Num primeiro momento a literatura de ficção científica serviu como canal para especulações e hipóteses acerca das reais capacidades humanas. Júlio Verne e outros escritores deram vida a projetos que no século XIX eram inexecutáveis, como uma viagem à Lua, ou ao centro da Terra, por exemplo. Após a literatura o cinema, que foi considerado por Edgar Morin a "aventura da imagem" (1975), também serviu como veículo para a expressão de grandes aventuras do espírito humano. George Meliés deu vida, em 1902, a uma película sobre o tema da aventura espacial lunar. Era a tentativa de estabelecer em bases icônicas novas possibilidades que se abriam para a aventura humana na Terra.

O Vale do Amanhecer recebeu, então, reflexos da cultura pós-moderna na construção de sua narrativa, assentada sobre um novo lugar da Humanidade no Cosmos e ilustrada com as possibilidades que o cinema e a ficção apresentam. Podemos ver esta articulação na figura 5, extraída da série Jornada nas Estrelas, que foi ao ar a partir de 1966 nos Estados Unidos e foi exibida no Brasil dois anos depois pela TV Excelsior.

Esta última figura já foi objeto de considerações por estudiosos do Vale, como CAVALCANTE (2008), que perceberam a imediata ligação com as referências do cinema sugerindo uma dinâmica de reprodução ou dependência cultural, o que não pretendemos tratar aqui. Nossa ponderação segue outro sentido, mais consoante à teoria bakhtiniana de dialogia, em que os componentes de um diálogo possuem plena autonomia e alteridade na interação. Segundo Faraco (2010), para Bakhtin 
(...) a compreensão não é mera experienciação psicológica da ação dos outros, mas uma atividade dialógica, que, diante de um texto, gera outro(s) texto(s). Compreender não é um ato passivo (um mero reconhecimento), mas uma réplica ativa, uma resposta, uma tomada de posição diante do texto (FARACO, 2010, p. 42).

E visto que o ato de compreender supõe a alteridade do outro enunciador, a interpretação - que passa por processos subjetivos - faz do interpretante praticamente um outro autor. Neste sentido as aproximações entre cinema e imagem serão sempre expressão própria da realidade do Vale e não alguma espécie de reprodução mimética.

Foi assim que as narrativas da ficção científica apresentaram-se como mediadoras para as novas categorias religiosas que a vidente Tia Neiva trazia à tona em seu profetismo; para os candangos que vieram atraídos pelas promessas majestáticas da cidade futurista, Neiva não poderia simplesmente profetizar usando categorias rurais. Por isto sua forma de ver e anunciar a outra realidade, que é uma narrativa de fronteira, se aproxima da ficção. O próprio Mário Sassi, esposo de Neiva e codificador da doutrina, reconhece a importância do gênero ficcional como recurso na expressão de realidades ainda não alcançadas pelas demais tradições religiosas, como a nova cosmologia, relatividade do tempo, vida em outros planetas, extraterrestres, outras dimensões da matéria, dentre outros:

Não parece lógico, portanto, pensar que as formas de vida, possíveis nesses outros mundos, devam ocorrer segundo conceitos de um dos menores dos mundos. Nesse sentido, a ficção científica é mais coerente que as concepções puramente científicas, que, aliás, são poucas (SASSI, 1990, p. 26, grifos nossos).

\section{Considerações finais}

Muito do que já foi escrito sobre o fenômeno religioso do Vale do Amanhecer leva em conta as categorias de hibridismo, bricolagem, sincretismo, assimilação ou identificação, conceitos estes que tentam delimitar sua polissemia. Porém as compreensões que percebemos até o momento o situam como resultado mais imediato da interlocução das matrizes religiosas brasileiras, quase um fenômeno exótico e endêmico, muito particular e muito restrito. Queremos retomar aqui (e 
não necessariamente na mesma ordem) três elementos anteriormente considerados: a construção de Brasília, a influência da nova cosmologia e a possibilidade de expressão da cinegrafia.

Chamamos a atenção para o fato de que o Vale reage, na verdade, a uma dinâmica de longa duração e, por isso, é uma das poucas expressões religiosas que se entende conceitualmente dentro da nova cosmologia, mas nem por isso nega a tradição cultural na qual está inserido. Entende o novo e preserva o antigo; situa caboclos, pretos velhos e índios no comando de naves estelares, na direção de planetas e na engenharia sideral da galáxia.

O cinema não é uma peça secundária naquela construção de mundo. Ele traz ao sertanejo, operário e candango não apenas divertimento, mas novas possibilidades de composição da realidade em um enredo que harmonizasse a promessa frustrada (que foi Brasília) com as esperanças novamente adiadas. $\mathrm{O}$ cinema possibilitou o nascimento de uma razão e o desenvolvimento de uma nova linguagem que abrangessem a realidade semi-imaginária humana. É o que Tia Neiva e Mário Sassi fazem ao enunciarem um outro mundo possível (a transcendência) em tons cinematográficos. Essa narrativa não é mera transposição do cinema, pois está carregada de sentidos próprios do contexto sociocultural em que se situam os ouvintes do Vale do Amanhecer; sobretudo tem uma mensagem a eles. Ao olhar as pinturas de Vilela destacadas aqui pode-se perceber a semelhança da trajetória dos personagens Tiãozinho e Justininha com as pessoas que ligaram suas vidas à construção da nova Capital. Tia Neiva fala da outra vida de Tiaozinho, mas está falando também da outra vida dos candangos.

Brasília é importante neste processo porque, de certa forma, é na construção da nova capital que se manifesta concretamente a percepção pós-moderna. Ficou muito difundida a comparação entre ela e uma cidade futurista ou de outro planeta. O traçado ímpar de suas construções demonstra ruptura com o antigo projeto arquitetônico barroco do império luso-brasileiro e quer apontar o futuro. Mas, ao mesmo tempo, a grande finalidade da nova cidade ainda é a mesma motivação sebastianista: o advento de um milênio redentor ao povo brasileiro. Contudo, à medida que Brasília nascia, mais pessoas chegavam para participar do prodígio. E com elas suas histórias, tradições e a forma de olhar o 
mundo, que depois seriam integradas em outra grande narrativa para recontá-lo. Isto se fez mais urgente quando aos poucos se percebeu que o novo eixo do mundo tinha apenas uma estética diferente com suas construções arrojadas mas era portador do mesmo ethos antigo da segregação e exclusão social. Não por acaso o Vale se posicionou na nova cosmologia portadora de uma temporalidade futura. No futuro, ainda que expresso em categorias cinematográficas, encontra-se a redenção e a graça.

\section{Referências}

ARMOND, Edgar. Os exilados de Capela. S/l; divulgação,1959.

BAKTHIN, Mikhail. Estética da criação verbal. São Paulo: Martins Fontes, 2000.

CAVALCANTE, Carmen Luísa Chaves. Dialogias no Vale do Amanhecer: os signos de um imaginário religioso. Fortaleza: Expressão Gráfica Editora, 2011.

FARACO, Carlos Alberto. Linguagem e diálogo: as ideias linguísticas do círculo de Bakhtin. São Paulo: Parábola Editorial, 2010.

MORIN, Edgar. O cinema ou o homem imaginário. Trad. Antônio-Pedro Vasconcelos. Lisboa: Moraes editores, 1970.

NEIVA, Tia. Pequenas Histórias: Tiãozinho e Justininha. Planaltina: Editora do Vale do Amanhecer, 1986.

RENDERS, Helmut. "A experiência religiosa pós-moderna e o fenômeno da aceleração em comparação com as temporalidades pré-moderna e moderna". In: Horizonte, Belo Horizonte, vol. 13, no. 37, p. 428-445, Jan./Mar. 2015.

RENDERS, Helmut. "Artefatos, imagens e logotipos como linguagens da religião: uma proposta multidisciplinar do estudo da cultural visual religiosa brasileira." In: NOGUEIRA, Paulo Augusto (org.). Religião e Linguagem (Linguagens da religião 2). São Paulo: Paulus, 2015b.

RENDERS, Helmut. "O coração como atributo hagiográfico de São Benedito do Rosário: hipótese sobre a sua origem e seu modelo subjacente da vida cristã". In: Horizonte. Belo Horizonte, vol. 13, n. 29, p. 109-132 (jan./mar. 2013)

ROSE, Gillian. Visual methodologies: an introduction to the interpretation of visual material. 2. ed. Los Angeles: Sage Publications, 2007.

SASSI, Mário. 2000: Conjunção de Dois Planos. Planaltina: Editora do Vale do Amanhecer, 1990 
SENRA, Nelson de Castro (org). Veredas de Brasília: as expedições geográficas em busca de um sonho. Rio de Janeiro: IBGE, Centro de Documentação e Disseminação de Informações, 2010.

SEEMANN, Jörn. "Arte, conhecimento geográfico e leitura de imagens: O geógrafo, de Vermeer". In: Pro-Posições. Campinas: Unicamp, vol. 20 n.3, p.43-60 (set./dez. 2009). 